\title{
Shedding light on the river and sea lamprey in western European marine waters
}

\author{
Sophie A. M. Elliott ${ }^{1,5, *}$, Noémie Deleys ${ }^{1,2}$, Etienne Rivot ${ }^{1,5}$, Anthony Acou ${ }^{1,3}$, \\ Elodie Réveillac ${ }^{4}$, Laurent Beaulaton ${ }^{1,6}$
}

\begin{abstract}
${ }^{1}$ Management of Diadromous Fish in their Environment OFB-INRAE-Institut Agro-UPPA, 35042 Rennes, France ${ }^{2}$ French Research Institute for Exploitation of the Sea (IFREMER) VIGIES, 44311 Nantes, France ${ }^{3}$ UMS OFB-CNRS-MNHN PatriNat, Station marine du Museum National d'Histoire Naturelle, 35800 Dinard, France ${ }^{4}$ Littoral, Environnement et Sociétés (LIENSs), UMR 7266, La Rochelle Université-CNRS, 17000 La Rochelle, France ${ }^{5}$ UMR ESE Ecology and Ecosystem Health, Institut Agro, INRAE, 35042 Rennes, France
\end{abstract}

${ }^{6}$ OFB, DRAS, 35042 Rennes, France

\begin{abstract}
Lampreys are ancestral jawless vertebrates with particularly complex life histories. Population declines resulting from increased anthropogenic pressure have been observed. For semelparous diadromous lampreys, the marine phase remains largely a black box, making targeted management and conservation measures difficult to implement. Here, we collated a database of 168904 hauls from both fisheries-dependent and fisheries-independent surveys between 1965 and 2019. Lampreys were observed in only 254 hauls ( $<1 \%$ lamprey presence); 421 sea lamprey Petromyzon marinus and 300 European river lamprey Lampetra fluviatilis were identified. Sizes ranged from 13 to $92 \mathrm{~cm}$ and from 14 to $42 \mathrm{~cm}$, respectively. The majority of lampreys (61\%) were caught by mobile demersal gear types. The highest presence of both species was recorded within the Greater North Sea, followed by the Bay of Biscay. L. fluviatilis was observed closer to the coast than P. marinus. For both lampreys, there was an increase in size with distance from the coast. $P$. marinus were predominantly $<60 \mathrm{~cm}$ and observed from August to February, indicating that these were sexually immature juveniles migrating out to sea. For L. fluviatilis, the majority were thought to be adults $(>20 \mathrm{~cm})$ and occurred in autumn, indicating inshore migration. Our observations provide insight into the ecology of lampreys at sea and highlight study locations and gear types, which may be more pertinent for future research. Greater awareness is needed during surveys to collate catch information on lampreys and improve understanding of their ecology and phenology at sea.
\end{abstract}

KEY WORDS: Endangered species · Lamprey · Distribution · Ecology · Growth · Migration · Surveys

\section{INTRODUCTION}

Lampreys are ancestral jawless vertebrates with complex life histories (Kelly \& King 2001, Potter et al. 2015). They occur within temperate waters of both the Northern and Southern hemispheres (Renaud 1997, Kelly \& King 2001). Three semelparous anadromous lamprey species have been identified in north-western European waters: the

\footnotetext{
${ }^{*}$ Corresponding author: sophie.elliott@agrocampus-ouest.fr
}

sea lamprey Petromyzon marinus (Linnaeus, 1758); the Arctic lamprey Lethenteron camtschaticum (Tilesius, 1811), which has only been observed in Sweden and therefore not considered hereinafter) (Maitland 1980, Potter et al. 2015); and the European river lamprey Lampetra fluviatilis (Linnaeus, 1758) (Potter et al. 2015). Very little is known about the distribution at sea of anadromous lamprey species.

(C) The authors 2021. Open Access under Creative Commons by Attribution Licence. Use, distribution and reproduction are unrestricted. Authors and original publication must be credited. 
The population status of $P$. marinus and L. fluviatilis is of major concern. During the late $20^{\text {th }}$ century, the, the combined impacts of increased targeted fishing in estuaries, river pollution, freshwater habitat destruction and engineering works such as the construction of dams led to their decline (Kelly \& King 2001, Beaulaton et al. 2008, Mateus et al. 2012, Lasne et al. 2015, Maitland et al. 2015). Climate change may also aggravate lamprey populations during their freshwater habitat occupancy (Lassalle \& Rochard 2009, Maitland et al. 2015).

Both $P$. marinus and $L$. fluviatilis are listed under the Habitat Directive (92/43/EEC), the Bern Convention (Appendix III) and the Barcelona Convention. $P$. marinus is also listed under the OSPAR convention (Maitland et al. 2015). While considered as Least Concern in the IUCN Red List in Europe (Freyhof \& Brooks 2011), both species are listed as vulnerable or endangered in many European countries (Mateus et al. 2012, Maitland et al. 2015, https://www.national redlist.org). For example, in France and Spain, where significant populations have been exploited (Beaulaton et al. 2008, Mateus et al. 2012), P. marinus is listed as endangered and vulnerable, respectively, and $L$. fluviatilis is listed as vulnerable and regionally extinct, respectively (Doadrio 2001, UICN Comité français et al. 2019).

The freshwater stages of the $P$. marinus and $L$. fluviatilis life cycle (spawning in rivers, larval stages, metamorphosis and downstream migration) are well characterised (e.g. Kelly \& King 2001, Maitland, 2003, Docker \& Potter 2019). The precise timings of migration to and from the sea vary with factors such as latitudinal clines and environmental conditions (e.g. temperature, rainfall), in addition to stream and river characteristics (Moser et al. 2015, Pavlov et al. 2017, Docker \& Potter 2019). However, ecological information on the marine phase of $P$. marinus and L. fluviatilis (e.g. host species and size preference, movement and distribution at sea, mortality, return migration cues) largely remains a black box. Such knowledge gaps make targeted management and conservation measures difficult to implement (ICES 2015, Hansen et al. 2016).

Adult $P$. marinus upstream spawning migration takes place from February to June in north-western European waters (Maitland 2003, Moser et al. 2015, Hansen et al. 2016). In south-western European waters, migration has been observed from December to June, with peaks from February to April (depending on populations) (Moser et al. 2015, Hansen et al. 2016). L. fluviatilis upstream migration can extend from July to June the following year, though they appear to have distinct autumn and spring runs (Maitland 1980, 2003, Moser et al. 2015). P. marinus and L. fluviatilis larval (ammocoete) stage duration in European waters is approximately 3 to 5 yr (Maitland 2003, Dawson et al. 2015, Hansen et al. 2016). During this phase, they feed on detritus and microorganisms within the soft sediment of rivers and streams (Taverny et al. 2012, Potter et al. 2015). Post-metamorphic $P$. marinus (approximately 10 to $22 \mathrm{~cm}$ ) downstream migration in north-western Europe takes place between late autumn and early winter (Maitland 1980, Bird et al. 1994, Quintella et al. 2003, Silva et al. 2013b, Hansen et al. 2016). Within south-western European waters, downstream migration has been observed between October and May, with peaks in February and March (Silva et al. 2013b, Hansen et al. 2016). Post-metamorphic L. fluviatilis $(9-17 \mathrm{~cm})$ downstream migration has been recorded from midwinter through to April (Maitland 2003, Dawson et al. 2015, Pavlov et al. 2017).

L. fluviatilis marine habitat occupancy is thought to last between 3 and 24 mo, whereas for P. marinus, it is between 10 and 28 mo (Beamish 1980, Halliday 1991, Silva et al. 2013a, Renaud \& Cochran 2019). In European waters, both lampreys have been observed to parasitise a range of hosts. In general, L. fluviatilis parasitises smaller species (e.g. clupeoids and gadoids) than $P$. marinus, which parasitises species of a wide range of sizes (e.g. clupeoids, salmonids to elasmobranchs and marine mammals) (Kelly \& King 2001, Maitland 2003, Lança et al. 2013, Silva et al. 2014, Renaud \& Cochran 2019). Adult L. fluviatilis migrating back to freshwater, range between 20 and $50 \mathrm{~cm}$ in size (mean $30 \mathrm{~cm}$ ) (Kelly \& King 2001, Mateus et al. 2012, Docker \& Potter 2019, Renaud \& Cochran 2019), whereas adult $P$. marinus can range from 60 to 122 cm (Hansen et al. 2016, Docker \& Potter 2019, Renaud \& Cochran 2019).

Given the recent declines in lamprey abundance, a better understanding of their ecology during their marine phase is needed. This would help determine threats posed to these species while at sea and identify conservation measures required to improve populations (Maitland et al. 2015). Here, we collated a substantial database of 168904 hauls which occurred in north-western European waters. The data were obtained from fisheries-independent (scientific surveys) and French fisheries-dependent data (from fishing vessels; Tables S1, S2 and Fig. S1 in the Supplement at www.int-res.com/articles/suppl/n044 p409_supp.pdf). Given the existing literature on the life history of lampreys, we expected to see spatial and size differences, with $P$. marinus having a more 
dispersed distribution and larger size ranges than $L$. fluviatilis (Maitland 2003, Potter et al. 2015). We also expected to observe periods during the year when lampreys migrate to and from marine waters and are more likely to be caught.

\section{METHODS}

\subsection{Survey data}

Fisheries-dependent and fisheries-independent data were collected within European waters (Greater North Sea, Celtic Sea, Bay of Biscay and Iberian coast, and Metropolitan French waters within the Mediterranean; Fig. 1 and Tables S1 \& S2). Fisheries-independent data from ICES were extracted from the Database of Trawl Surveys (DATRAS) portal (https://www. ices.dk/data/data-portals/Pages/DATRAS.aspx). Metropolitan French scientific surveys (excluding data available through DATRAS) were collated from the Institut Français de Recherche pour l'Exploitation de la Mer (IFREMER). Information from Regimbart et al. (2018), which highlights survey information on diadromous fish, was used to gather French scientific surveys (https://campagnes.flotteoceanographique.fr/ campaign; Table S1).

Fisheries-dependent data came from the observation of on-board fishing vessels, referred to as ObsMer (Cornou et al. 2015). ObsMer data are a collection of on-board catch data held by IFREMER and available on request from the French Ministry of Fisheries and Aquaculture (Direction des pêches maritimes et de l'aquaculture). ObsMer data provide targeted and bycatch, landed and discarded data from fishing vessels throughout the year within the Greater North Sea, the Celtic Sea, the Bay of Biscay and the Mediterranean. According to the sampling plan for ObsMer data, observers randomly sample professional fishing vessels and fishing operations when on board (Fauconnet et al. 2015).

Only fully processed and fully marine hauls, downstream of transitional waters, were taken into account. Due to missing data and insufficient information on the length of hauls, size of vessels, mesh size, etc., it was not possible to calculate catch per unit effort. Equally, the capture of lampreys at sea is directly related to the capture of their host and is therefore susceptible to vary depending on when in the haul the host was captured. Details on gear types, number of hauls and years the surveys were undertaken are outlined in Table S1. To help evaluate lamprey capture from the different surveys, gear cate- gories were identified from the type of gear they were caught with, whether the gear was static or mobile, and the water zone (pelagic, demersal or benthic) in which the gear was employed (Table S2).

For all surveys, the number of lampreys captured and some biological information (species, number of fish per haul, length and in some cases weight) were provided. However, because of the lack of information to quantify survey effort and variability in catch between gears and seasonal and spatial effort, only presence-absence and length data per haul were considered in the analysis.

\subsection{Frequency of occurrence}

As a result of the limited number of presence observations and associated difficulties in taking into account spatio-temporal heterogeneity, only simple robust statistical analyses were performed to avoid over-interpretation of the data. The initial data set contains less than $1 \%$ presence, making the analysis of presence-absence data very difficult. To understand the effect of distance from the coast on lamprey presence, all gear types, surveys and ICES divisions which did not contain lamprey presence were removed from the dataset, thus improving the balance ratio between presences and absences (Fielding \& Bell 1997). To further reduce zero inflation, the nonrandom spatial distribution of fisheries observer data, and the lack of knowledge of the precise location of capture (beginning or the end of the haul), the study area was downscaled and divided into a regular grid $\left(20 \mathrm{~km}^{2}\right)$. Grid cells of 10, 20 and $30 \mathrm{~km}^{2}$ were tested, but $20 \mathrm{~km}^{2}$ was found to be best to reduce zero inflation and yet not lose too much detail. For each grid cell, the central point was assigned a value of 1 if it contained a presence and a value of zero if no presence was recorded in the cell, as recommended by Aarts et al. (2012), Keil et al. (2013) and Pointin et al. (2018). This process brought the percentage of zeros to $98 \%$ for Petromyzon marinus and $96 \%$ for Lampetra fluviatilis.

Distance from the coast $(\mathrm{km})$ and season (spring [March-May], summer [June-August], autumn [September-November] and winter [DecemberFebruary]) were used to examine spatial variation of lamprey presence-absence, with gear and year included as random effects when significant (Eqs. 1 $\& 2$ ). Depth was not taken into account since it was not possible to obtain the precise depth at which lamprey presence was recorded. Binomial generalised linear models (GLMs) were used to quantify the 
effect of distance from the coast for both lamprey species. A complementary log-log link function was used since it is better adapted to data with more zeros (Zuur et al. 2009). Eqs. (1) \& (2) outline the model of best fit for both species.

$$
\begin{aligned}
\text { P. marinus } \mathrm{PA}_{i, j}= & \beta_{0, j}+\beta_{1, j} \times \text { Distance }_{i}+ \\
& \operatorname{RE}(\text { Gear }) \\
\text { L. fluviatilis } \mathrm{PA}_{i, j}= & \beta_{0, j}+\beta_{1, j} \times \text { Distance }_{i}+ \\
& \beta_{1, j} \times \text { Season }_{i}+\mathrm{RE}(\text { Gear })
\end{aligned}
$$

where $\mathrm{PA}_{i, j}$ is the complementary log-log probability of presence (link function), $\beta_{0, j}$ and $\beta_{1, j}$ are the parameters that depend on species $j$, $i$ refers to the number of samples and RE refers to the random effect. A post hoc Tukey's HSD test was used to identify differences between seasons. To identify whether one species presence was closer to the coast than the other, an ANOVA test was performed followed by a post hoc Tukey's HSD test on the species-specific parameters $\beta_{0, j}$ and $\beta_{1, j}$.

\subsection{Size}

For both species, length data were analysed using GLMs to explore the effect of distance from the coast and the existence of potential interactions between seasons and distance. To explore potential seasonal length differences in lampreys, all individuals were first modelled against season with distance from the coast. Since there were few large $P$. marinus, smaller individuals were then modelled against season. In line with literature on $P$. marinus post-metamorphic sexually immature sizes (e.g. Maitland 1980, Hansen et al. 2016), smaller individuals were characterised as less than $50 \pm 10 \mathrm{~cm}$. Since these smaller individuals were not observed in June and July, seasons were then categorised into 3 groups: summer to autumn (August-November), winter (December-February) and spring (March-April). To assess the robustness of our results for the definition of seasons, different combinations of months within the seasonal categories were also tested. Latitudinal variations in lamprey length were also explored using the above method to understand potential seasonal migration timing differences. Gear and year were included as random effects for significance. Eqs. (3) \& (4) outline the model of best fit for $P$. marinus and $L$. fluviatilis, respectively.

$$
\begin{aligned}
\text { P. } \text { marinus length }_{i}= & \beta_{0}+\text { Distance }_{i}+ \\
& \operatorname{RE}(\text { Year })+\varepsilon_{i} \\
\text { L. fluviatilis length } & =\beta_{0}+\text { Distance }_{i}+ \\
& \operatorname{RE}(\text { Year })+\varepsilon_{i}
\end{aligned}
$$

For all GLMs, the model of best fit was identified by the lowest Bayesian's information criterion (BIC). BIC was used instead of Akaike's information criterion since it performs better when there is heterogeneity in the dataset and the sample size is smaller (Brewer et al. 2016). Model significance was tested against the null hypothesis using a log-likelihood ratio test. All mapping and statistical analysis was undertaken in R CRAN free software (version 3.3, http://cran.r-project.org).

\section{RESULTS}

Between 1965 and 2019, 721 lampreys (421 Petromyzon marinus and 300 Lampetra fluviatilis) were identified from 68287 hauls from scientific trawl surveys and 100617 hauls from French fishing vessels (Table S3; Figs. 1 \& 2). In total, 254 hauls had lampreys present ( $<1 \%$ lamprey presence).

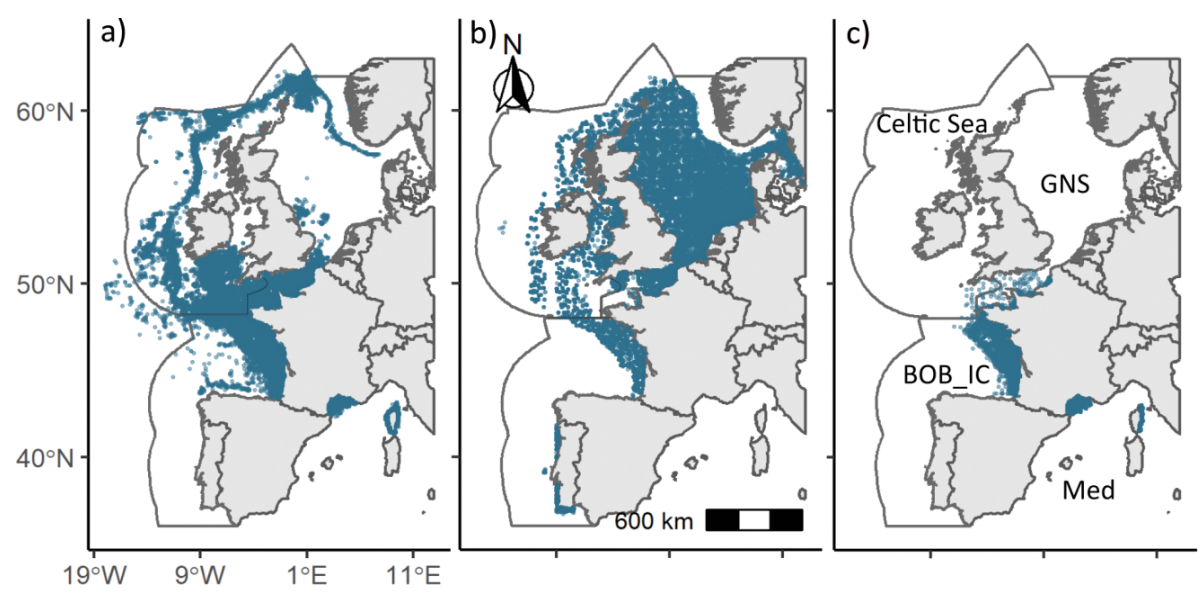

Fig. 1. Haul locations (blue dots) for (a) fisheries-dependent ObsMer surveys, (b) fisheries-independent ICES DATRAS submitted surveys and (c) French national scientific surveys analysed for the presence of lampreys. Black solid lines delineate ICES ecoregions. GNS: Greater North Sea; BOB_IC: Bay of Biscay and Iberian coast; Med: Mediterranean 


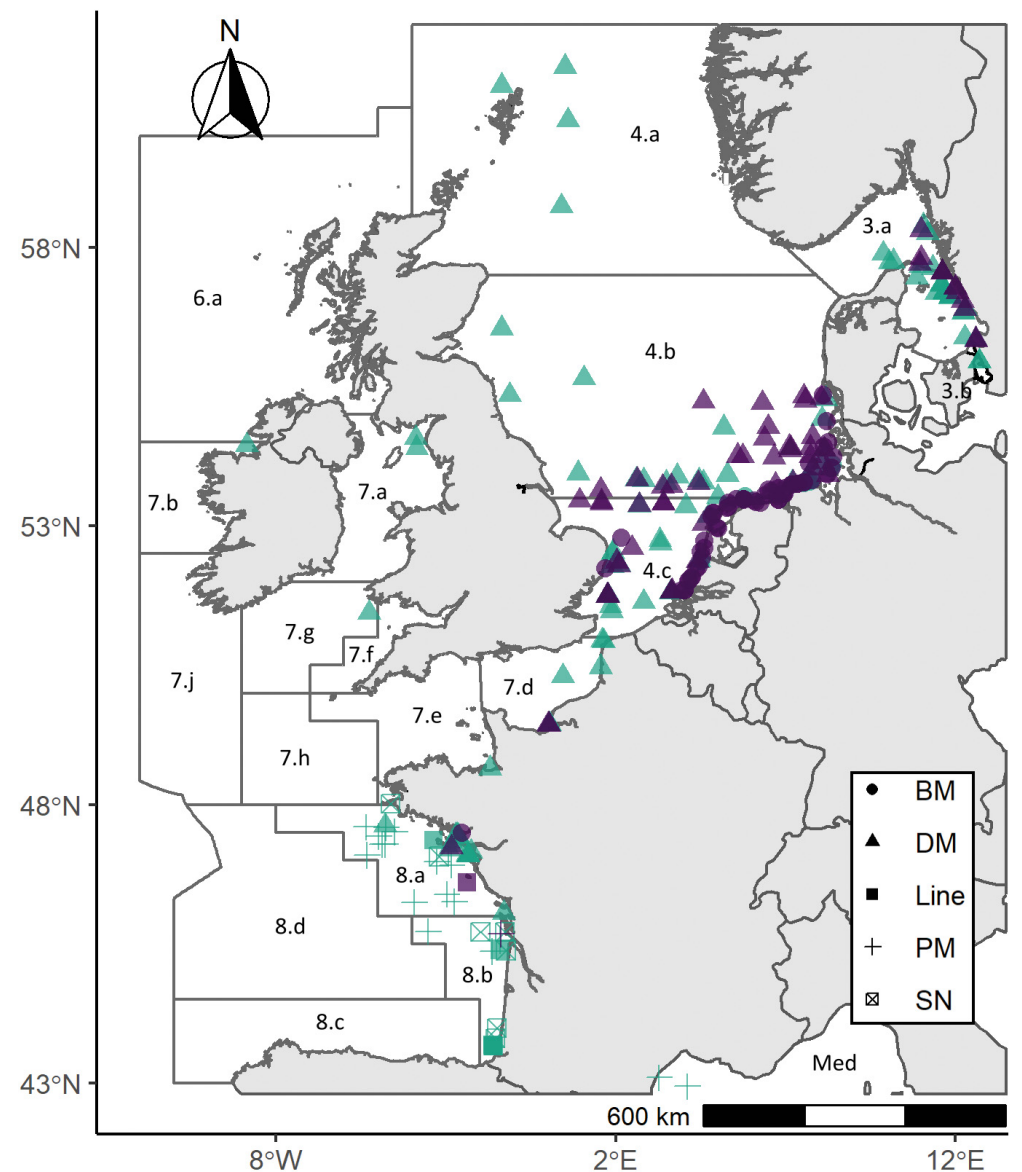

Fig. 2. Presence locations of Petromyzon marinus (green) and Lampetra fluviatilis (purple) caught by the different gear categories. BM: benthic mobile; DM: demersal mobile; PM: pelagic mobile; SN: seine net. Black solid lines delineate ICES statistical divisions. Refer to Table S2 for more detail

\subsection{Capture variations}

For both species, the presence of lampreys was higher from scientific bottom trawl surveys (SBTSs) submitted to ICES DATRAS (primarily North Sea International Bottom Trawl Survey [NS-IBTS], P. marinus $=84$ and $L$. fluviatilis $=114$ ) than from fisheriesdependent data $(P$. marinus $=23$ and $L$. fluviatilis $=2$ ) or French scientific surveys ( $P$. marinus $=27$ and $L$. fluviatilis $=4 ;$ Tables S3 \& S4). Mobile demersal gear caught the majority of both species (69\% for P. marinus and $52 \%$ for L. fluviatilis, primarily otter beam trawls from SBTSs; Tables S3, S4 \& S5). Benthic demersal gear types captured more $L$. fluviatilis than $P$. marinus (56 presences vs. 9 presences, respectively, primarily bottom beam trawls from the Demersal Young Fish Survey; Tables S3 \& S5). Although far fewer lampreys were caught by the fisheries-dependent data, a wider range of gear types targeting a variety of fish species caught lampreys (Tables S3 \& S6).

\subsection{Frequency of occurrence}

Presence of L. fluviatilis was highest in the Greater North Sea along the Dutch, Swedish and western German coasts (ICES divisions 3.a.21, 4.b and 4.c) (Fig. 2; Table S7). P. marinus presence was highest in the Greater North Sea, where samples were widely dispersed among open-sea and coastal locations (Fig. 2), followed by the Bay of Biscay (ICES division 3.a, 4.b-c and 8.a-b; Fig. 2; Table S7). L. fluviatilis occurrence was higher closer to the coast $(24.29 \pm 35.50 \mathrm{~km}$, mean $\pm \mathrm{SD})$ than for P. marinus $(36.21 \pm 49.91 \mathrm{~km}$; Tukey's HSD test $\mathrm{p}<0.05)$, whose distribution was more dispersed $(\mathrm{p}<0.001$, df $=2$, deviance explained $7 \%$; Figs. 2 \& 3; Table S3). L. fluviatilis was also observed closer to the coast in summer and autumn than in winter or spring (Fig. 3a.ii, Tukey's HSD test $\mathrm{p}<0.01$ and $\mathrm{p}<$ 0.05, respectively).

\subsection{Size}

$P$. marinus length ranged between 13 and $92 \mathrm{~cm}$, whereas L. fluviatilis length ranged between 14 and $42 \mathrm{~cm}$ (Table S3). An increase in $P$. marinus and $L$. fluviatilis length with distance from the coast was detected $(\mathrm{p}<0.001$, $\mathrm{df}=5$, deviance explained $4 \%$ and $\mathrm{p}<0.001$, $\mathrm{df}=5$, deviance explained $=3 \%$, respectively; Fig. 3b). On average, larger $P$. marinus were caught by mobile demersal gear than by other gear types (Fig. 3b). No clear statistical seasonal or latitudinal length differences were observed for either species (Fig. 3b).

Across the range of latitudes in which $P$. marinus were present, the smallest individuals were observed in winter. Too few large individuals were present to observe seasonal latitudinal differences. Since the majority of L. fluviatilis were observed in the North Sea, no seasonal latitudinal variation was detected.

Two length modes were detected for $P$. marinus, with the presence of larger individuals (greater than approx. $50 \mathrm{~cm}$ ) scattered across the course of the year and the presence of smaller individuals (less than approx. $40 \mathrm{~cm}$ ) with a higher frequency from August through to February (Fig. 4a.i, b.i). A higher percentage of $P$. marinus was observed at the beginning of the year (Fig. 4b.i), whereas a higher percentage of L. fluviatilis can be seen in autumn, with no clear seasonal size trend (Fig. 4a.ii, b.ii). 

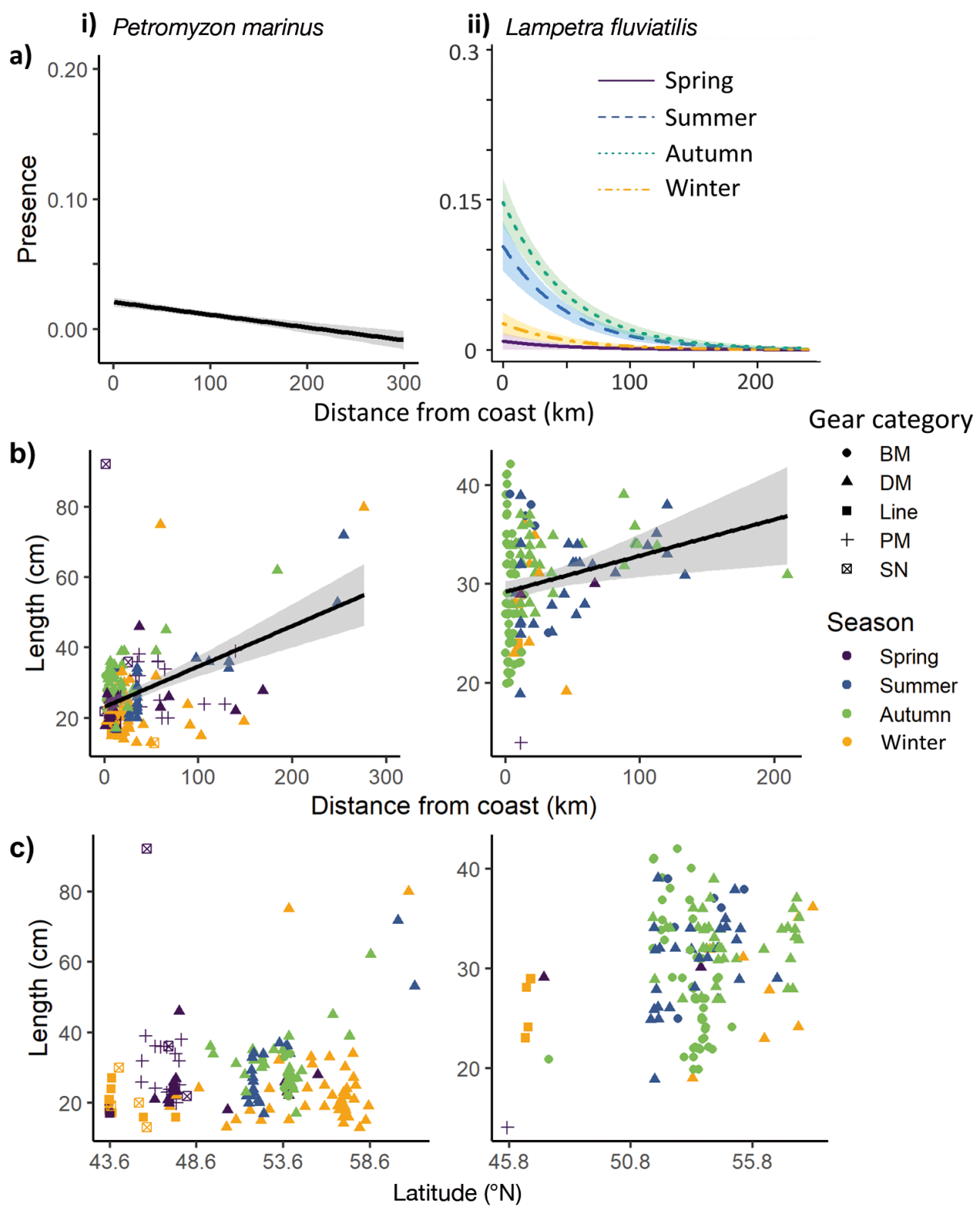

Fig. 3. (a) Presence with distance from the coast, with model fitted lines and shaded area indicating $\pm 95 \%$ CIs, (b) length with distance from the coast, with model fitted lines and the shaded area indicating $\pm 95 \%$ CIs, and (c) length with latitude for (i) Petromyzon marinus and (ii) Lampetra fluviatilis. BM: benthic mobile; DM: demersal mobile; PM: pelagic mobile; SN: seine net. Colours relate to season

\section{DISCUSSION}

The presence of lampreys was reported in less than $1 \%$ of hauls. Given the wide range of depths, gears types and regions where surveys were undertaken, the very low percentage of presence indicates a combination of rarity, low detectability and poor reporting rate. These results therefore highlight the difficulty in understanding the marine life history phase of lampreys.

\subsection{Capture}

Lampreys at sea live as an external parasite of host species, and their capture is almost entirely dependent on catching the host species. Lampreys have been observed to parasitise species which the fisheries-dependent data were targeting (e.g. gadoids, mullet, hake), indicating a link between the abundance of the targeted fish and the abundance of lampreys (Silva et al. 2014, Renaud \& Cochran 2019). 

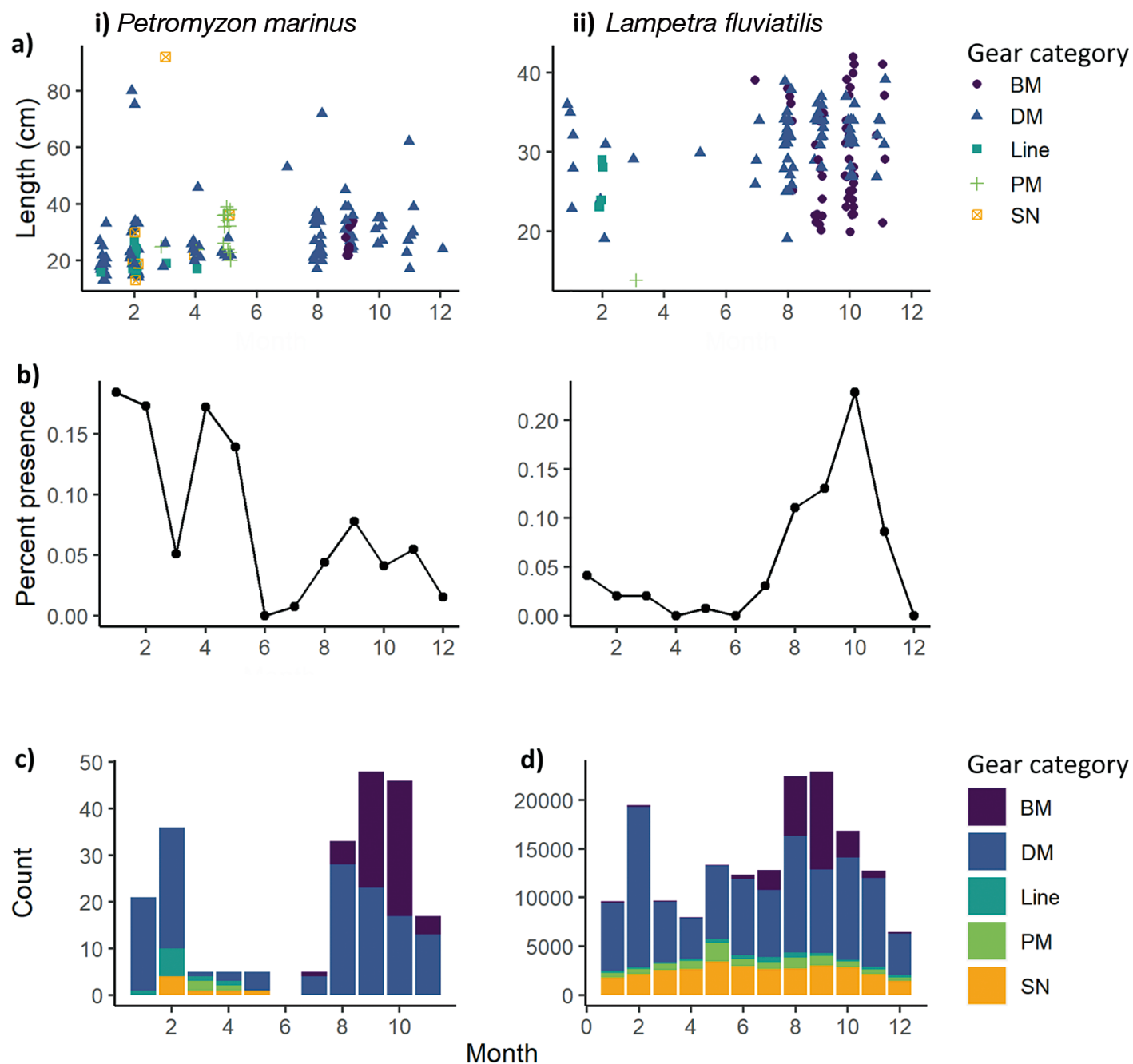

Fig. 4. (a) Lengths by month and (b) percent presence per month for (i) P. marinus and (ii) L. fluviatalis. (c,d) Gear category stacked histograms of lamprey length data per month (c) and total number of hauls per month (d). BM: benthic mobile; DM: demersal mobile; PM: pelagic mobile; SN: seine net

However, clear information on lamprey hosts is sparse, with no definitive trends other than attacking species which may be more abundant and have thinner skin (Renaud \& Cochran 2019). The lack of confirmed lamprey host trends hinders targeted lamprey surveys. In our database, presence of both lamprey species was higher where mobile demersal gear was used, indicating that the majority of lamprey hosts may be demersal species. Lança et al. (2014) also found a relationship between benthic hosts and Petromyzon marinus, possibly as a result of declines in pelagic-preferred hosts such as shads and salmonids (Merg et al. 2020). Insufficient survey information was available to calculate catch per unit effort for each gear type, making it difficult to accurately quantify rates of gear or métier capture (which considers the gear and target species).
A greater proportion of lampreys were observed from the fisheries-independent data than from the fisheries-dependent data. Since lampreys may detach themselves from their hosts at the time of capture (Halliday 1991), the higher presence of lampreys from scientific surveys may be as a result of the shorter hauls in scientific surveys and, hence, reduced likelihood of disturbance and the greater likelihood of the parasitic lamprey remaining attached to the host fish. Alternatively, parasitic species may not have necessarily been recorded within fisheriesdependent surveys. Thiel et al. (2009) analysed lamprey catch from commercial published records and fisheries research data within the Baltic Sea. Although very few observations were made, more lampreys were recorded from fisheries-dependent data (5 records, $9.3 \%$ ) than from scientific surveys (1 record, 
$1.8 \%$ ). From our database, more lampreys were caught from mobile demersal gear across northwestern European waters. The greater presence of lampreys by scientific data will therefore probably have been because of the larger number of scientific hauls within the southern North Sea. Information on lamprey stocks across Europe is sparse (Beaulaton et al. 2008, Thiel et al. 2009, Mateus et al. 2012, ICES 2015, Silva et al. 2017).

\subsection{Frequency of occurrence}

Although our database contains trawls from across the European distribution of both species (Maitland 2003), neither of the 2 species was found in all ICES ecoregions. Lampetra fluviatilis presence was closer to the coast than $P$. marinus, which was more dispersed; this finding is in line with existing literature (e.g. Maitland 2003, Thiel et al. 2009, Potter et al. 2015). L. fluviatilis was recorded in only 2 ICES ecoregions (the Greater North Sea and the Bay of Biscay and Iberian coast), whereas $P$. marinus was also found to occur in the Celtic Sea and the Mediterranean. The higher presence of both species in the Greater North Sea and the Bay of Biscay may have been a result of the greater sampling effort within these regions.

The presence of $L$. fluviatilis was particularly high along the coast of Germany and Holland within the south-eastern North Sea. Despite this being a heavily fished sea (Berg et al. 1996) few published papers have referred to $L$. fluviatilis presence within this area (e.g. Admiraal et al. 1993, Thiel \& Salewski 2003, Pavlov et al. 2017). Conversely, few L. fluviatilis were observed off the coast of the Humber estuary, even though significant captures and a commercial fishery exist further upstream within the River Derwent and the River Ouse (Jang \& Lucas 2005). The majority of surveys within the North Sea came from DATRAS bottom trawl surveys and NS-IBTSs, which are undertaken between August and February. According to Jang \& Lucas (2005), the main pre-spawning upstream migration period for $L$. fluviatilis in the River Derwent is between November and February. This slight mismatch in dates between surveys and lamprey migration may therefore explain the few presences observed in this area of the UK.

No lampreys were observed along the Iberian coast where populations are known to exist (Quintella et al. 2003, Mateus et al. 2012, Silva et al. 2017). This may be because the majority of hauls were under- taken within the Greater North Sea. Lança et al. (2014) found that $P$. marinus migrate to deeper oceanic regions off the Iberian west coast. The majority of hauls analysed within this study were closer to the coast, with few samples off the Iberian coast, which may explain the lack of either lamprey species observed within this region. Furthermore, the surveys undertaken within this region were from Portuguese IBTSs, which take place between September and November, before seaward and upstream $P$. marinus migration takes place (Silva et al. 2013a, Moser et al. 2015, Hansen et al. 2016).

\subsection{Size}

The majority of $P$. marinus caught were less than $40 \mathrm{~cm}$, with a higher presence of small $P$. marinus between autumn to spring. These observations indicate that the $P$. marinus were most likely post-metamorphic sexually immature individuals migrating into marine waters (Quintella et al. 2003, Silva et al. 2013b, Hansen et al. 2016). Most P. marinus were small individuals, most likely because the majority of surveys took place in waters closer to the coast, where small individuals would be present in greater numbers, prior to any dispersal of the host fish.

Although no statistical seasonal latitude variations in small $P$. marinus were observed, the wide range in size of $P$. marinus less than $40 \mathrm{~cm}$ may partially be due to latitudinal variations of post-metamorphic migration to marine waters. More northerly populations are known to migrate in autumn to winter and more southerly populations migrate in winter to spring (Silva et al. 2013a, Hansen et al. 2016). The wide range in size of small $P$. marinus may also indicate that juveniles stay close to the coast for these initial seasons before migrating further offshore. Alternatively, some individuals may choose to migrate into marine waters later in the year and at a larger size (King \& O'Gorman 2018).

A bimodal length tendency was observed for P. marinus, with the majority of small individuals $(<40 \mathrm{~cm})$ present from autumn to spring, when metamorphosed seaward migration is considered to take place (Silva et al. 2013a, Hansen et al. 2016). The few large $(>60 \mathrm{~cm})$ individuals were found further from the coast and caught over the course of the year. These results corroborate with existing literature (e.g. Halliday 1991, Silva et al. 2013a) that P. marinus occupy marine waters for over a year, given that large and small individuals were observed in autumn and winter. 
Although fewer hauls were undertaken during summer months, proportionally far fewer lampreys were observed, albeit the ratio of gear types remained the same. Mortality of adult lampreys at sea (e.g. from potential lack of hosts) is poorly understood (Maitland et al. 2015, Hansen et al. 2016), but bycatch fishing mortality at sea appears to be low (Stratoudakis et al. 2016) as opposed to targeted fishing mortality within estuaries (Beaulaton et al. 2008). Fewer individuals were identified in summer, potentially as a result of offshore migration to deeper waters further from the coast (Lança et al. 2014). Larger P. marinus may parasitise larger species (e.g. cetaceans and larger elasmobranchs) (Halliday 1991), which are rarely caught in fisheries-dependent and fisheriesindependent surveys. Cetaceans and elasmobranchs also often migrate long distances. Lamprey wounds on marine mammals are nonetheless rare (Renaud \& Cochran 2019, W. Dabin unpubl. data), and lamprey host size selectivity tendencies are not clear (e.g. Swink 1991).

The majority of L. fluviatilis were observed in autumn, with a mean length of $30 \mathrm{~cm}$. This corresponds with adults returning to freshwater to spawn (Maitland 2003, Dawson et al. 2015), given that adult size ranges from 20 to $50 \mathrm{~cm}$ (Maitland 1980). A bimodal length frequency for $L$. fluviatilis was not evident. Since the majority of $L$. fluviatilis were caught in autumn within $50 \mathrm{~km}$ from the coast and appeared to be adults, our results support the hypothesis that $L$. fluviatilis occupy marine waters for considerably less time (less than a year) than $P$. marinus (Docker \& Potter 2019, Renaud \& Cochran 2019). Furthermore, few individuals were observed over the course of the summer and L. fluviatilis is not known to migrate far from the coast (Maitland 2003, Thiel et al. 2009, Potter et al. 2015).

Increased coastal sampling from February to May, when $P$. marinus and $L$. fluviatilis return to rivers, may help improve the understanding of growth at sea. Tagging studies may be better adapted to understand lamprey migration timing and mortality at sea (Silva et al. 2013a). However, the probability of recapture has been observed to be low (e.g. Silva et al. 2013a), potentially because both lamprey species discussed here adopt the suitable river strategy rather than homing to natal streams (Moser et al. 2015). Furthermore, microacoustic tags have only recently been developed (Mueller et al. 2019), and minimum lamprey size for acoustic implants is $14 \mathrm{~cm}$ (Mueller et al. 2019).

Conservation measures have been set up across the globe to try and restore lamprey populations (e.g. rebuilding programs, improved river connectivity, removal of barriers and weirs, spatial areas of conservation) (Renaud 1997, Thiel et al. 2009, Maitland et al. 2015). As for many diadromous fish, most of those conservation measures concern the freshwater phase of the life cycle. Setting efficient conservation measure at sea is difficult because of our lack of understanding of the ecology and phenology of lampreys at sea. From our database, there were too few presence observations to identify a critical spatio-temporal window to be protected. Fishing mortality from bycatch does, however, seem to be low. Although lamprey sighting from hauls was low, greater awareness is needed in both fisheries-dependent and fisheries-independent surveys to collate more data on non-target species such as lampreys. On-deck examinations of landed fish for signs of lamprey scarring could provide substantial additional information (King 1980, King \& O'Gorman 2018). This might be feasible for scientific surveys but the logistics would be difficult with large samples on board commercial fishing vessels. Nonetheless, such information could provide additional information and help unravel important aspects of lamprey life history during their marine life history phase. This could help improve our understanding of threats to lamprey survival and implement more targeted conservation measures, such as temporal spatial closures within estuaries when adults migrate back to freshwater.

Acknowledgements: We thank the funders of the project Management of Diadromous Fish in their Environment, OFB-INRAE-Agrocampus Ouest-UPPA. We are extremely grateful to all those who were involved in collecting and compiling the fisheries-dependent and fisheries-independent surveys. We are also grateful to IFREMER and the French marine fisheries and aquaculture administration (DPMA) for access to their data. Finally, we thank the reviewers for their valuable contribution.

\section{LITERATURE CITED}

Aarts G, Fieberg J, Matthiopoulos J (2012) Comparative interpretation of count, presence-absence and point methods for species distribution models. Methods Ecol Evol 3:177-187

* Admiraal W, van der Velde G, Smit H, Cazemier WG (1993) The rivers Rhine and Meuse in The Netherlands: present state and signs of ecological recovery. Hydrobiologia 265:97-128

Beamish FWH (1980) Biology of the North American anadromous sea lamprey, Petromyzon marinus. Can J Fish Aquat Sci 37:1924-1943

* Beaulaton L, Taverny C, Castelnaud G (2008) Fishing, abundance and life history traits of the anadromous sea lamprey (Petromyzon marinus) in Europe. Fish Res 92: 90-101 
Berg S, Krog C, Muus B, Nielsen J and others (1996) Red List of lampreys and marine fishes of the Wadden Sea. Helgol Meeresunters 50:101-105

Bird DJ, Potter IC, Hardisty MW, Baker BI (1994) Morphology, body size and behaviour of recently-metamorphosed sea lampreys, Petromyzon marinus, from the lower River Severn, and their relevance to the onset of parasitic feeding. J Fish Biol 44:67-74

Brewer MJ, Butler A, Cooksley SL (2016) The relative performance of $\mathrm{AIC}, \mathrm{AIC}_{\mathrm{C}}$ and $\mathrm{BIC}$ in the presence of unobserved heterogeneity. Methods Ecol Evol 7:679-692

* Cornou AS, Quinio-Scavinner M, Delaunay D, Dimeet J and others (2015) Observations à bord des navires de pêche professionnelle. Bilan de l'échantillonnage 2014. Ifremer, Nantes

Dawson HA, Quintella BR, Almeida PR, Treble AJ, Jolley JC (2015) The ecology of larval and metamorphosing lampreys. In: Docker MF (ed) Lampreys: biology, conservation, and control, Vol 1. Springer, Dordrecht, p 75-137

Doadrio I (ed) (2001) Atlas y libro rojo de los peces continentales de España. Dirección General de Conservación de la Naturaleza, Museo Nacional de Ciencias Naturales, Madrid. https://www.miteco.gob.es/es/biodiversidad/ temas/inventarios-nacionales/atlas_libro_rojo_peces_ tcm30-98786.pdf (accessed 18 Sep 2020)

Docker MF, Potter IC (2019) Life history evolution in lampreys: alternative migratory and feeding types. In: Docker MF (ed) Lampreys: biology, conservation, and control, Vol 2. Springer, Dordrecht, p 287-409

Fauconnet L, Trenkel VM, Morandeau G, Caill-Milly N, Rochet MJ (2015) Characterizing catches taken by different gears as a step towards evaluating fishing pressure on fish communities. Fish Res 164:238-248

Fielding AH, Bell JF (1997) A review of methods for the assessment of prediction errors in conservation presence/absence models. Environ Conserv 24:38-49

Freyhof J, Brooks E (2011) European Red List of freshwater fishes. Publications Office of the European Union, Luxembourg

Halliday RG (1991) Marine distribution of the sea lamprey (Petromyzon marinus) in the northwest Atlantic. Can J Fish Aquat Sci 48:832-842

Hansen MJ, Madenjian CP, Slade JW, Steeves TB, Almeida PR, Quintella BR (2016) Population ecology of the sea lamprey (Petromyzon marinus) as an invasive species in the Laurentian Great Lakes and an imperiled species in Europe. Rev Fish Biol Fish 26:509-535

ICES (2015) Report of the workshop on lampreys and shads (WKLS), 27-29 November 2014, Lisbon, Portugal. ICESCM 2014/SSGEF:13. https://www.ices.dk/sites/pub/Publica tion\%20Reports/Expert\%20Group\%20Report/SSGEPD/ 2015/01 \% 20WKLS\%20-\%20Report\%20of\%20the \% 20 Workshop \% 20on \% 20Lampreys \% 20and\%20Shads.pdf (accessed 9 Apr 2020)

Jang MH, Lucas MC (2005) Reproductive ecology of the river lamprey. J Fish Biol 66:499-512

Keil P, Belmaker J, Wilson AM, Unitt P, Jetz W (2013) Downscaling of species distribution models: a hierarchical approach. Methods Ecol Evol 4:82-94

Kelly FL, King JJ (2001) A review of the ecology and distribution of three lamprey species, L. fluviatilis, L. planeri and P. marinus. Biol Environ Proc R Ir Acad B 101:165-185

King EL Jr (1980) Classification of sea lamprey (Petromyzon marinus) attack marks on Great Lakes lake trout (Salvelinus namaycush). Can J Fish Aquat Sci 37:1989-200
King JJ, O'Gorman N (2018) Initial observations on feeding juvenile sea lamprey (Petromyzon marinus L.) in Irish lakes. Biol Environ Proc R Ir Acad B 118:113-120

* Lança MJ, Machado M, Ferreira R, Alves-Pereira I, Ruivo Quintella BR, Raposo de Almeida PR (2013) Feeding strategy assessment through fatty acid profiles in muscles of adult sea lampreys from the western Iberian coast. Sci Mar 77:281-291

* Lança MJ, Machado M, Mateus CS, Lourenço M, Ferreira AF, Quintella BR, Almeida PR (2014) Investigating population structure of sea lamprey (Petromyzon marinus, L.) in western Iberian Peninsula using morphological characters and heart fatty acid signature analyses. PLOS ONE 9:e108110

Lasne E, Sabatié MR, Jeannot N, Cucherousset J (2015) The effects of dam removal on river colonization by sea lamprey Petromyzon marinus. River Res Appl 31:904-911

Lassalle G, Rochard E (2009) Impact of twenty-first century climate change on diadromous fish spread over Europe, North Africa and the Middle East. Glob Change Biol 15: 1072-1089

* Maitland PS (1980) Review of the ecology of lampreys in northern Europe. Can J Fish Aquat Sci 37:1944-1952

Maitland PS (2003) Ecology of the river, brook and sea lamprey. Conserving Natura 2000 Rivers, Ecology Series No. 5. English Nature, Peterborough. http://publications.naturalengland.org.uk/publication/75042 (accessed 26 Nov 2020)

Maitland PS, Renaud CB, Quintella BR, Close DA, Docker MF (2015) Conservation of native lampreys. In: Docker MF (ed) Lampreys: biology, conservation, and control, Vol 1. Springer, Dordrecht, p 375-418

Mateus CS, Rodríguez-Muñoz R, Quintella BR, Alves MJ, Almeida PR (2012) Lampreys of the Iberian Peninsula: distribution, population status and conservation. Endang Species Res 16:183-198

Merg ML, Dézerald O, Kreutzenberger K, Demski S, Reyjol Y, Usseglio-Polatera P, Belliard J (2020) Modeling diadromous fish loss from historical data: identification of anthropogenic drivers and testing of mitigation scenarios. PLOS ONE 15:e0236575

Moser ML, Almeida PR, Kemp PS, Sorensen PW (2015) Lamprey spawning migration. In: Docker MF (ed) Lampreys: biology, conservation, and control, Vol 1. Springer, Dordrecht, p 215-263

Mueller R, Liss S, Deng ZD (2019) Implantation of a new micro acoustic tag in juvenile Pacific lamprey and American eel. J Vis Exp 145:e59274

* Pavlov DS, Zvezdin AO, Kostin VV, Tsimbalov IA, Kucheryavyy AV (2017) Temporal characteristics of downstream migration of smolts of the European river lamprey Lampetra fluviatilis in the Chernaya River. Biol Bull 44: 290-295

* Pointin F, Cornou AS, Prod'homme R, Taupin N, Rochet MJ (2018) A method to address the non-random spatial distribution of on-board observer data to map landings and discards. Fish Res 199:242-251

Potter I, Gill HS, Renaud CB, Haoucher D (2015) The taxonomy, phylogeny, and distribution of lampreys. In: Docker MF (ed) Lampreys: biology, conservation, and control, Vol 1. Springer, Dordrecht, p 35-73

\% Quintella BR, Andrade NO, Almeida PR (2003) Distribution, larval stage duration and growth of the sea lamprey ammocoetes, Petromyzon marinus L., in a highly modified river basin. Ecol Freshwat Fish 12:286-293 
Regimbart A, Guitton J, Le Pape O (2018) Zones fonctionnelles pour les ressources halieutiques dans les eaux sous souveraineté française. Deuxième partie: inventaire. Rapport d'étude. Les publications du Pôle halieutique Agrocampus Ouest no. 46, Rennes. https://hal.archivesouvertes.fr/hal-02293032/ (accessed 9 Jan 2019)

Renaud CB (1997) Conservation status of Northern Hemisphere lampreys (Petromyzontidae). J Appl Ichthyol 13: 143-148

Renaud CB, Cochran PA (2019) Post-metamorphic feeding in lampreys. In: Docker MF (ed) Lampreys: biology, conservation, and control, Vol 2. Springer, Dordrecht, p 247-285

Silva S, Servia MJ, Vieira-Lanero R, Barca S, Cobo F (2013a) Life cycle of the sea lamprey Petromyzon marinus: duration of and growth in the marine life stage. Aquat Biol 18: $59-62$

Silva S, Servia MJ, Vieira-Lanero R, Cobo F (2013b) Downstream migration and hematophagous feeding of newly metamorphosed sea lampreys (Petromyzon marinus Linnaeus, 1758). Hydrobiologia 700:277-286

Silva S, Araújo MJ, Bao M, Mucientes G, Cobo F (2014) The haematophagous feeding stage of anadromous populations of sea lamprey Petromyzon marinus: low host selectivity and wide range of habitats. Hydrobiologia 734: 187-199

Silva S, Vieira-Lanero R, Barca S, Cobo F (2017) Densities and biomass of larval sea lamprey populations (Petromyzon marinus Linnaeus, 1758) in north-western Spain and

Editorial responsibility: Brendan Godley, University of Exeter, Cornwall Campus, UK

Reviewed by: 3 anonymous referees data comparisons with other European regions. Mar Freshw Res 68:116-122

Stratoudakis Y, Mateus CS, Quintella BR, Antunes C, Raposo de Almeida P (2016) Exploited anadromous fish in Portugal: suggested direction for conservation and management. Mar Policy 73:92-99

Swink WD (1991) Host-size selection by parasitic sea lampreys. Trans Am Fish Soc 120:637-643

* Taverny C, Lassalle G, Ortusi I, Roqueplo C, Lepage M, Lambert P (2012) From shallow to deep waters: habitats used by larval lampreys (genus Petromyzon and Lampetra) over a western European basin. Ecol Freshwat Fish 21:87-99

Thiel R, Salewski V (2003) Verteilung und Wanderung von Neunaugen im Elbeästuar (Deutschland). Limnologica 33:214-226

* Thiel R, Winkler HM, Riel P, Neumann R and others (2009) Endangered anadromous lampreys in the southern Baltic Sea: spatial distribution, long-term trend, population status. Endang Species Res 8:233-247

*UICN Comité français, MNHN, SFI, AFB (2019) La Liste rouge des espèces menacées en France-chapitre poissons d'eau douce de France métropolitaine. Comité français de l'UICN, Paris. https://inpn.mnhn.fr/docs/LR_ FCE/liste_rouge_poissons_eau_douce_metropole_2019_ fascicule.pdf (accessed 1 Jul 2020)

Zuur AF, Leno EN, Walker NJ, Saveliev AA, Smith GM (2009) Mixed effects models and extensions in ecology with R. Springer-Verlag, New York, NY

Submitted: May 25, 2020

Accepted: January 11, 2021

Proofs received from author(s): April 13, 2021 